\title{
INCUBATING A SLOW PEDAGOGY IN PROFESSIONAL ACADEMIC DEVELOPMENT: AN ETHICS OF CARE PERSPECTIVE
}

\author{
K. S. Collett* \\ Department of Education Studies \\ e-mail: kcollett@uwc.ac.za \\ C. L. van den Berg* \\ Department of Information Systems \\ e-mail: cvandenberg@uwc.ac.za

\section{B. Verster**} \\ Department of Town and Regional Planning \\ e-mail: versterb@cput.ac.za
}

\section{Bozalek*}

Directorate of Teaching and Learning

e-mail: vbozalek@uwc.ac.za

*University of the Western Cape

Cape Town, South Africa

${ }^{* *}$ Cape Peninsula University of Technology

Cape Town, South Africa

\section{ABSTRACT}

The current neoliberal impetus in higher education has effects on all aspects of academic life, including professional academic development. These effects include increasing workloads and more casualisation of academic work, particularly teaching and a greater emphasis on quantification of scholarly outputs. The Slow movement provides an alternative way for valuing academic life (Berg and Seeber 2016; Bozalek 2017; Hartman and Darab 2012; Martell 2014; Ulmer 2017), as does the ethics of care, which has been used as a normative framework to evaluate and re-imagine academic development from a different perspective than that of neoliberalism (Bozalek et al. 2014; Tronto 2010). To date, however, there has been little engagement with how Slow pedagogy (Berg and Seeber 2016) might be put into conversation with an ethics of care to re/configure professional academic development. Our article addresses this gap by diffractively reading the political ethics of care (Tronto 1993; 2013) through the concept of a Slow pedagogy in order to reimagine creative provocations for academic development. Experiences of a group of participants, who attended inter-institutional academic development courses in Cape Town, are drawn upon to illustrate the superpositions of these diffractive readings. The intra-actions in face-to-face and online meetings and artefacts are analysed to see what was 
helpful for the development and flourishing of the small group of participants using the new insights gained through the diffractive readings. Findings show how a professional development course, informed by elements of care ethics and Slow pedagogy, enhance the sustainability of professional learning communities.

Keywords: slow pedagogy, professional academic, development, political ethics of care

\section{INTRODUCTION}

The current neoliberal impetus in higher education has effects on all aspects of academic life, including professional academic development. These effects include the audit culture which has led to increased administrative loads and bureaucratisation of teaching, increased staffstudent ratios, the casualisation of teaching, as well as pressure to publish as quickly as possible to increase financial rewards for the institution. The Slow movement provides an alternative way of valuing academic life, in areas such as Slow science (Stengers 2005, 2011), Slow pedagogy (Berg and Seeber 2016; Hartman and Darab 2012; Martell 2014) and Slow scholarship (Bozalek 2017; Garey and Hertz 2014; Ulmer 2017). This alternative movement in academia is created through acknowledgement of collaboration and the building of interdisciplinary communities of practice; allocating time for internal reflection and mentoring in scholarship of teaching and learning; a focus on an ethics of care in the way in which we interact with and acknowledge each other; embracing Slowness and caring collectively; fostering collaboration and collective engagement in addressing and challenging neoliberal discourse and practice. Mountz et al. $(2015,1244)$ argue that a commitment to Slow scholarship, "fostered by academic alliance and friendships, can help us to come out of moments of depression or exhaustion, lest we drown in shame, loss and discontentment". These experiences are not unfamiliar in the neoliberal higher education landscape.

The political ethics of care has gained acknowledgement in the recent past as a normative framework to evaluate and re-imagine professional academic development from a different perspective than that of neoliberalism (Bozalek et al. 2014; Tronto 2010). However, with the exception of a paper by Mountz et al. (2015), who engage with Slow scholarship and how a feminist politics of resistance to neoliberalism in higher education can be achieved through collective action using care ethics, there has been little engagement with how Slow pedagogy may be put into conversation with an ethics of care for professional academic development.

Professional academic development is widely acknowledged as being central to growth in higher education and student achievement (Boyer 1990; Bozalek and Dison 2013). Increasingly attention has been focused on the scholarship of teaching and learning to advance scholarship in the field and achieve goals related to social justice in higher education systems across the 
world (Boyer 1990; Leibowitz and Bozalek 2016). This article focuses on the development of the scholarship of teaching and learning by three academics (small group participants) and one facilitator who participated in two professional development courses, and how they built rapport amongst one another.

The two inter-institutional professional academic development courses were offered by the Cape Higher Education Consortium (CHEC), as part of the Quality Teaching in Higher Education (QTHE) short courses offered across the four higher education institutions in the Western Cape. The political ethics of care as a normative framework and Slow pedagogy are diffracted through each other to analyse our engagement and to propose a more enlarged perspective of what it may mean to develop and transform as academics at a university.

Case study data from our experiences as small group participants on two professional academic development QTHE short courses is drawn on. We focus on particular processes of building trust and deepening learning through the giving and receiving of feedback and sharing our reflections as critical friends in both face-to-face and online environments. We conclude with insights on the application of Slow pedagogy within a political ethics of care framework.

\section{ENGAGEMENT WITH THE LITERATURE}

Increasingly scholars have critiqued the influences of neoliberalism on the functioning of public universities globally (Radice 2013; Olssen and Peters 2005; Suspitsyna 2012). The corporatisation of higher education institutions (HEIs) demand these institutions being "... impelled by governments to adopt, to varying extents, the neoliberal values of competition, privatization, efficiency and self-reliance ...." Hartman and Darab $(2012,52)$.

The effects of corporatisation experienced by academics manifest through increased performance management and individual accountability (Meyerhoff, Johnson and Braun 2011; Slaughter and Rhoades 2000). These include pressure for higher performance targets in scholarly output; professionalisation of teaching and learning and increased community engagement. At the same time resources to enhance staff and student support decrease while class sizes increase. The \#FeesmustFall Movement in South African HEIs expresses some of the manifestations of these tensions, as well as the increased pressure on HEIs and staff to enable student access to higher learning and a continuous increase in the throughput rate. The demands of academic life are further increased by the speed of change brought on by digital technology and the need for lecturers to be skilled in aligning pedagogy and technology to the benefit of their students (Laurillard 2013). This speed of change coupled by the increased pressure within the neoliberal environment results in lecturers losing their sense of achievement, focus and identity (Hanson 2009). Joseph (2017) refers to this to as “... academics 
losing their agency".

Hartman and Darab (2012) argue that universities should be environments within which professional development and scholarship is able to thrive through the provision of space, time and resources. Mountz et al. $(2015,1236)$ highlight the relative silence about "the isolating effects and embodied work conditions of such increasing demands".

Mountz et al. $(2015,1244)$ contend that "the business enterprise of academic life in the neoliberal university produces a work rhythm that is rushed, riddled with anxiety and pressures to be ever-present. Overwhelming pressures can lead to paralysis and scholarship can come to a complete halt." The performance measuring tools used in academia are, in many cases still dominated by the lecturing timetable first and foremost to determine the dreaded full time equivalent (FTE). The FTE has been used for many years as the most prominent indicator to determine academic workload (Olssen and Peters 2005). Meyerhoff, Johnson and Braun (2011) and Mountz et al. (2015) call for a way of working within a neoliberal context that enhances and changes the way we use time, through collective and collaborative work that embraces the notion of a Slow pedagogy.

\section{SLOW PEDAGOGY}

The Slow food movement started a concern with quality rather than efficiency and output and also placed an emphasis on using local produce. Carla Petrini (2007), the originator of the Slow Food Movement made explicit that Slow does not have to do with speed, but rather a thoughtful and attentive approach. The Slow movement has now spread to many areas such as Slow Cities, and also in academia, Slow Science Slow Scholarship, Slow Pedagogy, Slow Ontology, and Slow Philosophy, the premise being that quality should not be compromised by the pressure of time that prioritises speed, efficiency and output (Berg and Seeber 2016; Boulous Walker 2016; Stengers 2011; Ulmer 2017). These different uses of Slow all emphasise depth of engagement, interdisciplinarity and the importance of making practices pleasurable for the participants (Bozalek 2017).

In the culture of increased pressure to produce measurable outcomes within predetermined curriculum constructs and ever increasing technological advances in society at large and in higher education (Bozalek et al. 2014; Olssen and Peters 2005), slowing down seems to be the antithesis of what needs to happen. By Slowing down, or decolonising time, we are able to reconnect with ourselves and others and nurture relationships to improve the quality of life and work (Shahjahan 2014).

Academics are well aware of the tendency that going Slow (by creating time, space and allocate resources to activities other than teaching such as scholarly reflection, thinking, 
reading, writing, debating etc.) is not valued and actually seen as being unproductive (Garey and Hertz 2014; Mountz et al. 2015; Shahjahan 2014). Ulmer (2017, 201) calls for an understanding of the above predicament not as "... unproductive, but as differently productive". Ulmer further asks the very relevant question of "What if scholars adopted a Slow ontology?" (2017, 202).

In this article we explore how a Slow pedagogy enables one to disengage from an instrumentalist approach to teaching and learning. It results in an alternative way of being, which would create space for an authentic and deep level of engagement and support on our practice as "new" academics. This was the original motivation for the small group participants to engage in a series of professional academic development courses. A diffractive view of Slow pedagogy through a political ethics of care requires one to disperse time and bring in aspects of collaboration, attentiveness, responsibility, competence, responsiveness and trust. These aspects require time to incubate and mature into professional academic practice.

\section{ETHICS OF CARE}

Joan Tronto's political ethics of care $(1993,2013)$ is gaining attention in the development of higher education professional development practices (Bozalek et al. 2014; Bozalek et al. 2016; Zembylas, Bozalek and Shefer 2014). Bozalek et al. (2014) also found that the ethics of care provided a meaningful framework through which participants in a HEI professional development programme could evaluate their practice. They found that the framework helped to reveal moral elements and perspectives on human interaction such as differential power relations, collaborative work and raising awareness of the care needs of both participants and facilitators (Bozalek et al. 2014). They also found the framework to be useful in revealing public and political dimensions of care.

Fisher and Tronto (1990, 40, cited in Tronto 2013, 22) define care at a general level as "a species activity that includes everything that we do to maintain, continue, and repair our 'world' so that we can live in it as well as possible". Tronto, asserts that this includes an interrelationship between "our bodies, ourselves and our environment ..." (2013, 22). Fisher and Tronto (1990) and Tronto's (2013) notion of care as a holistic and systemically connected private and political practice, shifts care from the private and family domaine to the public and macro-political level. This conceptualisation of care is particularly informative considering the forces at play within the current neo-liberal university context in South African HEI's and globally.

The table below expands upon the phases or steps of care as identified by Fisher and Tronto (1990) and Tronto (2013), as well as the five moral elements of care related to these phases. The five phases of care and associated moral elements are elaborated on in the 
diffractive reading of our findings. These are set out here in summary to help guide engagement by the reader.

Table 1: The phases and corresponding moral elements of care. (Tronto 1993, 2013)

\begin{tabular}{|l|l|l|}
\hline Phase of Care & \multicolumn{1}{|c|}{ Explanation of phase } & $\begin{array}{c}\text { Moral element associated } \\
\text { with phase }\end{array}$ \\
\hline Caring about & noticing/recognising people's needs & Attentiveness \\
\hline Caring for & $\begin{array}{l}\text { once the need is recognised, it is necessary to take } \\
\text { responsibility to ensure that people's needs are met. }\end{array}$ & Responsibility \\
\hline Caregiving & the actual hands-on physical work of caring for people & Competence \\
\hline Care receiving & responding to the care that is given by the caregiver & Responsiveness \\
\hline Caring with & $\begin{array}{l}\text { the reiteration of the process of care, where habits and } \\
\text { patterns of care emerge through time }\end{array}$ & Trust and solidarity \\
\hline
\end{tabular}

\section{CONTEXT AND PARTICIPANTS}

The authors of this article were participants in two higher education staff development courses offered by the Cape Higher Education Consortium in 2016. They represent two different HEI's namely the University of the Western Cape and the Cape Peninsula University of Technology, and lecture in diverse disciplines. They shared a common interest in enhancing collaborative learning through technology and the design of their learning processes. All small group participants and the group facilitator were working mothers, juggling the demands of their professional and academic lives with parenting and caregiving.

The first QTHE short course aimed to enhance the use of technology in the design of teaching and learning processes and the second QTHE short course focused on the development of research proposals related to the professionalization of teaching and learning. Both QTHE courses followed a similar design: modelling aspects of best practice in higher education professional academic development. A blended learning design was used which infused weekly face-to-face sessions with online engagement related to formative assessment over a six week period which ended in a summative presentation and a written task. Online engagement was facilitated through a Google Docs platform where feedback and reflection on assessment tasks were shared, as well as through a range of applications available on mobile phones.

The small group participants and facilitator did not know each other prior to these courses and were allocated to interest groups at the onset of the course and were supported by a group facilitator, as well as a range of specialist presenters. The three participants and the facilitator were participants in the same small group in both courses. At the end of the course the small group participants also kept a written record of their post course reflections as part of their data collection. Active modelling of best practice in teaching and learning was built into the design of both courses and was used extensively by the small group participants. 
The CHEC short course titled "Designing Learning with Technologies" provided training and enabled the participants to actively engage with different types of technology and take what they learned to their own teaching practice. Knowledge and practice in the use of technology in the design of learning, enabled participants to apply technology tools to accomplish a variety of different tasks. This course was followed by a second course on "Designing a Research Proposal". This short course extended our capacity for scholarly research on our teaching and learning practices.

In both courses learning was driven by formative and summative tasks using Google Docs which encouraged the giving and receiving of feedback and small group participant collaboration. The practice of sharing reflective journals with each other and commenting on each other's reflections helped to raise personal thoughts and feelings into the public domain. In this way issues could be engaged with and support from small group members could be accessed.

Both formative and summative tasks and participant feedback were allocated credits towards course completion. Assessment and task templates provide the scaffolding for course requirements. The assessment strategy that was followed for this particular course focussed learning of participants and empowered us to appropriately act on the clearly stipulated demands.

\section{METHODOLOGY}

The research methodology is located within a participatory action research approach (McNiff 1993). The unit of analysis is a qualitative case study (Yin 2009) of a small group of three participants and facilitator as insider researchers. As action researchers we were directly involved in the process of systematically recording and reflecting on our practice, in order to understand and improve it.

The research site was located at the Cape Peninsula University of Technology Campus in Bellville where the QTHE courses took place in the first and second terms of 2016. Ethical permission to conduct this research was obtained from the University of the Western Cape in 2016. Case study data was drawn from the lived experiences of ourselves as three participants and a course facilitator were part of both courses and the same small group. Data used in this study included on-line feedback comments (referred to as reflective comments) on formative and summative tasks from Google Docs; reflective journals entries and reflective reports, Participatory Learning and Action (PLA) drawings and post course reflective meeting notes. Data was selected from each of the participants' reflective comments and reflective reports or journals, as well as the post-course reflective meeting notes that held a common resonance and 
ignited our interest and passion on this course, by drawing on the concept of data that "glows" (MacLure 2013, 661). The content of each of the data sets was scanned for themes, words and expressions that related to Tronto's five phases of care and Slow pedagogy.

\section{A DIFFRACTIVE METHODOLOGY}

Diffraction, a concept first proposed by feminist theorist Donna Haraway (1992) and then elaborated upon by Karen Barad $(2007 ; 2014)$ through her interpretation of quantum physics, means 'to break apart in different directions' (Barad 2007, 168), which happens where sound, water or light waves interfere with each other, combine and overlap or bend when they encounter an obstruction and create diffraction patterns. Waves can be amplified by being superimposed upon one another in their combination. Barad proposes that a methodology can be developed from this physical process of diffraction which engages affirmatively with difference.

Diffraction is an ethical and care-full practice of reading texts/oeuvres/approaches in their fine details, doing justice to them, and recognising the value of past, present and future knowledge contributions - not leaving behind or turning away from these contributions. Diffraction is thus a useful feminist methodological tool as it moves away from "reflective, disinterested judgment to mattering, embedded involvement" (Kaiser and Thiele 2014).

A diffractive methodology is non-representationalist (MacLure 2013) in that it does not reflect the world from the outside but assumes that we are all part of the world, entangled in it and implicated in everything - thus it is not possible to extricate oneself from the world. Barad and others like Van der Tuin (2011) have used a diffractive methodology to attentively and carefully read oeuvres, disciplines and texts through one another, looking for the fine details of differences that matter in order to create new insights into a phenomenon. Barad notes that "[d]iffractive readings bring inventive provocations; they are good to think with. They are respectful, detailed, ethical engagements" (Van der Tuin and Dolphijn 2012, 50).

Using a diffractive methodology made it possible for the political ethics of care and Slow pedagogy to "interrupt each other productively" (Haraway in Schneider 2005, 149). A diffractive methodology does not pit one theory against another or engage in trashing the ideas of the one and eulogising the other, but reads the one through the other.

Tronto's five phases of care and the associated moral qualities and Slow pedagogy were thus diffractively read through each other in order to consider our experiences in face-to-face and online interaction. Collective analysis of our data with these diffractive readings made it possible for new insights to develop. Barad $(2007,381)$ refers to ".. phenomena intra-actively produced and entangled with other phenomena ...". 


\section{ANALYSIS OF THE PROFESSIONAL ACADEMIC DEVELOPMENT PROCESS USING A DIFFRACTED POLITICAL ETHICS OF CARE FRAMEWORK AND SLOW PEDAGOGY APPROACH}

Below each of the phases of care is elaborated upon individually and then in relation to the data. It should be considered that each of the other phases of care can be understood as being "nested within it" (Tronto 2013, 49).

\section{“Caring about” as associated with Attentiveness}

Caring about is identified by Fisher and Tronto (1990, 40, cited in Tronto 2013, 22) as the first phase of care. Where "someone or some group notices unmet caring needs" (ibid., 40). Attentiveness is identified by Tronto as the moral or ethical quality that align with this phase of care, which requires "a suspension of one's self-interest, and a capacity genuinely to look from the perspective of the one in need. (In fact, we might also be attentive or inattentive to our own needs.)" (Tronto 2013, 34). Caring about takes into account the "uniqueness of each person's position" (Bozalek et al. 2014, 451).

On the course, caring about each other and being attentive was structured through the establishment of small groups sharing a common purpose, as well as through peer feedback on tasks and the co-reading of each other's weekly reflective reports. These processes helped us to communicate our needs for support and the aspects we wished to collaborate on. Our activity on the course with the use of technology, as well as the design of the sessions in small groups was directed towards attentiveness. In her reflections a participant wrote:

"Common focus around collaboration was the initial hook to link the people with one another. What enhanced this level of attentiveness further was a shared professional role as lecturers and the need to enhance our teaching and learning with the infusion of technology." (Course 1: Reflective Report).

Attentiveness was further facilitated by feedback being linked to an individual assessment mark. A focus on attention to and caring about the needs raised by others was experienced online and in face-to-face sessions. The structured feedback and reflective tasks helped to cement the bonding of relationships within the group and the development of a caring culture. As one participant notes:

"These weekly reflective reports were a structured opportunity to 'look inward' and a safe space to share one's fears and struggles. This sharing of our personal journey cemented the relationships or bond that was needed on a personal level and not just a professional level to be attentive to each 
other." (Post-Course 2: Reflective Notes).

Structured reflective tasks helped to both identify needs and consolidate a common focus on collective problem solving, while at the same time giving feedback on tasks ensured that assessment needs were acknowledged.

The activity of reflection as a structured individual and group activity both enabled attentiveness and reinforced attentiveness and caring. When attentiveness was facilitated through technology, it enhanced and prolonged the time-frame for attentiveness, as illustrated in the following comment by a participant:

\footnotetext{
"Reflection allowed two things, it forced you to slow down: we had to reflect interpersonally look inward and it gave you permission to be human making the personal connection much easier. Safe haven giving you an opportunity to slow down, look inward and connect with your personal self. Integrating the personal and the professional and deep layers of being. Slow gives you the opportunity to connect holistically. Accessing support online 24/7 between group members provided the space for considered and caring feedback asynchronously." (Post-Course 2: Reflective Notes)
}

The nature of structured and shared reflective exercises throughout the duration of the course required us to qualitatively engage and be attentive to articulate our own needs for support. Thus attending to the critical elements of self-care within a political ethics of care, often a neglected focus in our work and providing a space within the demands of the neoliberal context we are obliged to survive in. The small group participants and the facilitator experienced the value of technology as enabling extended opportunities to build social cohesion by connecting, engage in Slow scholarship and listening more "carefully" to the needs expressed by each other.

\section{“Caring for" as associated with Responsibility}

The second phase of care is caring for, (Fisher and Tronto 1990, 40, cited in Tronto 2013, 22). In this phase of care "someone or some group has to take responsibility to make certain that these needs are met" $(1990,40$, cited in Tronto 2013, 22). The moral quality of this phase of care manifests as Responsibility - where "someone or some group has to take on the burden of meeting those needs" (Tronto 2013, 34). Rather than responsibility being identified as an obligation it needs to be understood within an ethics of care - as a willingness to do something "embedded in a set of implicit cultural practices rather than a set of formal rules ..." (Tronto 1993, cited in Bozalek et al. 2014, 452). Tronto (2013) defines caregivers as those that respond to or meet the needs of other and care receivers as those whose needs are met.

The design and facilitation of the courses created a supportive, collegial space where 
participants could take part in a Slow scholarship and articulate how they needed to be supported. Both the caregivers and the care-receivers responded to the needs of others at a personal and professional level through feedback on tasks and via reflective exercises. As one of the small group participants noted, "Forced structure pushed me out of my comfort zone" (Course 1, reflective comment). While another participant commented "The community support, you are being held up" (Course 1: Reflective Comment). Although responding to needs was initially driven by assessment requirements, as the relationship between the small group participants strengthened, responding became deeper, more informal and familiar and a shared moral responsibility, as reflected in this comment, "The sense of shared responsibility ... the fact that I knew someone was waiting for my comments ..." (Post Course 2: Reflection Notes). Sharing our reflections and needs for support throughout the course and through collective processes helped to elevate our needs from a private to a collective level. We were thus able to practice a communal caring, a caring that "... comes out of hiding in private time and space" (Mountz et al. 2015, 1247).

Being able to raise one's needs collectively and to support each other's needs helped to reinforce the trust relationship that was built over time. The use of different technologies further enabled responsiveness and also allowed the small group participants to vary and Slow the pace of responding to each other. However, the quality of affinity and relatedness between small group participants was an essential "warming" factor that incubated a nurturing environment within which to be responsive to a range of personal and professional needs. As one participant put it, "The need to get permission to go Slow, comes from relationship" (Post Course 2: Reflective Notes). Bozalek et al. $(2014,452)$ asserts that "in a context of neoliberalism, it is necessary to find alternative spaces where responsibility rather than obligation can be a motivating impetus for engagement".

While technology enabled participants to be responsive to giving feedback; thus engaging in Slow scholarship; we experience the pacing and timing of feedback responses (related to complex tasks) as well as the complexity of tasks as increasing the pace and causing distress. As illustrated in this quote, "Experiencing a blended learning environment as a participant particularly with the focus on engaging with new technologies to facilitate learning created a great deal of cognitive dissonance and propelled my learning in new ways" (Course 1: Reflective Report). Engagement with information technology held both possibilities and contradictions for us.

Having our needs for support responded to by colleagues and facilitators was built into the design of the courses. By facilitators (traditional caregivers) holding back from providing feedback and comment before participants (care receivers) had begun to engage, was 
experienced (retrospectively) as an important step in building participant confidence and ownership to respond to the support needs of others. Initially participants were hesitant to provide a depth of comment in their feedback although they had been given the responsibility for this and a level of scaffolding on what type of feedback is most useful. Bozalek et al. (2016, 835 ) in reflecting on their feedback practices, found that feedback process may be improved by "explicitly encouraging participants to communicate what types of feedback and on which particular issues feedback would be most beneficial ...”. Small group participants in our courses initially held back as they were expecting the facilitator (as the traditional caregiver) to play a more dominant role here "make the first move". This response by a small group participant illustrates the extent to which care responsibilities were engaged with on the course and the value this had in raising their awareness of how they provided feedback to students. "The real learning came in reflecting on how we are learning about feedback by giving feedback and what we need to put in place for our own students when they engage in these processes" (Post Course

\section{2: Reflective Notes).}

Defining the expectations for feedback roles as well as building in mechanisms to monitor how care needs were met, were experienced as critical to building trust between caregivers and care-receivers. Our experience also raised our awareness of the importance of spending time to pay attention to these aspects and Slowing down to ensure connection.

\section{"Care-giving" as associated with Competence}

Care-giving is the third phase of caring identified by Fisher and Tronto (1990, 40 cited in Tronto 2013, 22). This phase "requires that the actual caregiving work be done" (Tronto 2013, 22). Care-giving manifest through the moral quality of competence. Tronto asserts that the quality of competence requires one "To be competent to care" and is "not simply a technical issue, but a moral one" (Tronto 2013, 35).

Tronto (1993) makes the point that material and other resources such as time and skill are needed to ensure caring can be done competently. The investment of participants in online resources enabled a level of care-giving and receiving beyond the confines of the course and the respective HEI's. The giving of time within which to learn long after formal working hours was motivated through wanting to both keep connected in order to deepen personal and professional bonds. Technology enabled us to reconnect to each other at a "place" and "pace" that helped to incubate (Slow) competence in caregiving and care-receiving in developing our professional practice.

Both facilitator and small group participants were caregivers on the course, with the facilitator playing a key role in the overall design, theoretical input and pacing of the 
curriculum. A small group participant reflected: "The guidance of CHEC instructors provided a framework to engage with exploring a range of technologies using a more informed approach. The range of literature and the constant feedback as well as link to electronic sites stimulated my learning and reflection" (Course 1: Reflective Report).

The moral element of competence by the facilitator was experienced through the course design, theoretical input, mediation of knowledge and the sensitive way in which they provided feedback. The naming of our group facilitator as a "gentle giant" captures in essence her modelling of these levels of competence.

Good role modelling in course design - informed by the principles of constructive alignment (Biggs 2014), blended learning and participatory action learning, was experienced as critical to providing the scaffolding that built the competence of care-receivers. The competence of the facilitator also built trust by care-receivers in their ability to achieve competence. Care-receiver experienced the facilitator "walking the talk". A participant comment captures this sentiment:

“... other group members agreed on the impact of the modelling of blended learning in this course and how it provides us with scaffolding in thinking about the development of our own courses out of what we have experienced .... Through being in the class community I felt I was being inducted into an 'apprenticeship' of good teaching and learning." (Course 1: Reflective Report).

Small group participants experienced what we called "a double dose of care and support" as we benefited both personally and professionally and course learning and strategies could often translate directly into innovations in practice. A participant reflected, "As a result of connecting with my peers on the CHEC course and being exposed to practices of other lecturers I have incorporated a number of other technologies into supporting both my planning and delivery of my teaching" (Course 1: Reflective Report). All small group participants experienced the building of their own competence through actively engaging in the role of being care-givers and care-receivers. They were perceived by colleagues in their own departments as individuals who could provide advice and support to other colleagues on aspects of teaching and learning as the "more knowledgeable" other.

While technology helped to open up space where Slow and considered connections could be made, inadequate consideration of the time it took to develop mastery of new technical skills, reduced the level at which small group participants experienced facilitators as being competent to respond to their needs. A participant expressed this as follows: "Different skills set, some people not confident with technology, Slowed things down but also created high levels of anxiety and venting in the group." (Post Course 2: Reflective notes). This highlights the need 
for careful consideration of timing and pacing of course activities in relation to the expected competencies to be developed. This is particularly relevant to the engagement of technology to support teaching and learning. Our experience highlights the need to pay attention to the timing and pacing of course activities, particularly when introducing new technologies in the learning process. It calls for the need to Slow down the pace to incubate and assimilate complex deep level learning.

\section{“Care-receiving" as associated with Responsiveness}

The moral quality of this phase manifests as the moral quality of responsiveness. Tronto elaborates: "The person cared for need not be the one who completes the process of responding, but some response is necessary" (Tronto 2013,35). Through the sharing of our reflective reports and giving and receiving of feedback, small group participants and the facilitator were able to identify where needs were not being met. A participant comments on the benefit she received from the collaborative learning process:

"I really enjoyed being able to read the writing and ideas of other colleagues and felt like I went on a cherry picking spree. This was great. I was learning so much by the reading and sharing I had access to from my peers. (Nice turn of phrase, good reference, new theory etc.). I am learning so much more quickly and being exposed to so much my brain feels like it is in overdrive. In this process I can feel stages of cognitive dissonance but this does not last for long as I seem to be taking leaps and bounds ...." (Course 1: Reflective Comment.)

Learning and responding collaboratively enhanced the extent to which we were learning both from each other and from the facilitator. A small group participant made this comment: "When commenting on other people's work, it felt as if I was learning as much as that person" (Course 1: Reflective Comment).

The design of a number of formative feedback tasks that culminated in a summative task drove our activity of both completing our tasks and giving feedback to others. The linking of feedback activities to a formal assessment mark increase the extent to which participants engaged responsively and with depth of feedback. As illustrated in this comment by a small group participant:

"The learnings per week have culminated into an end product that I can use and build upon. I forced myself to stop questioning and to believe in what I am doing and just get on with it. The course helped to create a space to look at what I am doing and the impact thereof. I have gained more confidence about the journey forward and feel that the course has helped me to shift some of my doubts and uncertainties." (Course 1: Reflective Report.) 
Technology afforded all small group participants the opportunity to get an enhanced level of responses from both facilitators and large group participants on their tasks. The use of technology also enabled the facilitator to get feedback on the value of the course content and process in an ongoing way. On-line connections helped us to Slow down and deeply connect with each other about both the content and process of our learning. This helped to enable minor adjustments in the course process.

While both the facilitator and small group participants were responsive to the needs of each other the pace of engagement during the six week course was intense and often limited the time for deeper engagement. A small group participant's comment reflects this need to engage in Slow pedagogy to try and deepen understanding and learning.

\footnotetext{
"In our group I also felt that I wanted more time to be able to follow up on some of the feedback that they had given me in the written form. I felt we needed a gap to consolidate and share key questions or ideas with group members - before we went on to the next section (jumping through hoops too fast). It made me wonder if we could not find other ways of maybe catching our breath and ideas after the session but still linking with group members on a face to face level to follow up on feedback etc.” (Course 1: Reflective Comment).
}

The blended learning design while promoting responsiveness also contributed to enhancing the pace of the course and range of activities participants were required to engage with. Interpersonal connection and learning was often fast paced during face-to-face sessions, however, the on-line pace could be Slowed down when individuals could take time to be responsive to feedback comments.

\section{“Caring with" as associated with Trust and Solidarity}

Tronto (2013) links caring with democratic practice. She asserts that, "This final phase of care requires that caring needs and the ways in which they are met need to be consistent with democratic commitments to justice, equality, and freedom for all” (Tronto 2013, 22). The moral quality of this phase of caring manifests as "Plurality, communication, trust and respect; solidarity caring with" (Tronto 2013,35). The supportive and caring collegial environment in our small group and with our facilitator helped to sustain our commitment to building trust and solidarity. The guiding and calming influence of our "gentle giant" helped to influence a culture of care and Slow pedagogy within the group as we grappled with our own feelings of incompetence and fragmentation. As a participant reflected:

"Within this storm we manage to find this safe haven, so it was meant for academic development but it was more, it was personal development. The importance of creating a space to be able to 
learn within a creative environment, this needs to be fostered and cultivated." (Post Course 2: Reflective Notes).

Another aspect that built trust was the differences in experiences, skills, and knowledge sets adding value to the small group. Not having the interpersonal baggage of colleagues in our own HEIs and Faculties helped to develop trust, a small group participant commented it was "Easier to make connections outside of my department, freedom to link outside of the constraints" (Course 1: Reflective Comment). Sevenhuijsen $(1998,11)$ helps us to understand this by showing that in groups, trust is influenced by "hierarchy or asymmetry in power relations".

Developing our competence through being attentive and responsive to each other's needs and encouraging one another to "keep going", "not give up" and "do the next course" (Course 1: Reflective Comments) helped to show collective caring and trust. Having a common purpose and working towards building the competence of each other over a period of time also built trust and strengthened our sense of solidarity as those authors who were participants began to identify as a group, - a group with a name "CHEC mates". A group with a mission to support each other in the development of our practice. A small group participant notes:

\footnotetext{
"Building on what we did on the CHEC course and developing it into the research focus and having the support of our facilitator to get us writing, to present and possibly publish. This is great scaffolding for our own trajectory in academic development. Makes me think about the logical structure of attending these CHEC courses. It is great to build on the insights and relationships formed in the other courses and feels like a real community of practice and expertise developing." (Course 2: Reflective Comment).
}

Time was needed to build trust through getting to know, to care and to rely on each other. The experiences of the small group participants supports Tronto's $(2013,5)$ view that trust "builds as people realize that they can rely upon others to participate in their care and care activities". This highlights the need to create spaces for continuity of contact as well as making time for the deepening of engagement and learning to enable a Slow pedagogy.

Continuity of contact and maintaining the group membership (consisting of the three participants), over two courses helped to build group cohesion. Building cohesion required the small group participants and facilitator to take time to get to know each other (Slow down) and to keep connected, as this quote illustrates:

\footnotetext{
"The feedback from peers and facilitator was extremely helpful as was the process of engaging with other member's research and providing feedback to them. Doing the previous CHEC course has helped me to place the activities into context and use some of the previous learnings." (Course 2: Reflective Comment).
} 
The closing comments between the small group participants and the facilitator express the sense of solidarity, joy and social cohesion that developed through participation in courses where a political ethic of care and a Slow pedagogy were holistically integrated into the design and facilitation. Testimony to the role of the course facilitator in practicing and integrity of care the "whole care process must fit together in order for good care to take place" (Bozalek et al. 2014, 457).

Participant 1: "It does not happen often that you become part of a group that share the level of trust, empathy and care that we have. It is really special and I am glad we are taking it further."

Participant 2: "Thank you for the shared learning we did. It was great to have you in our group and going through all the highs and lows together."

Participant 3: "Thanks to you it was so good to work with you again and to learn from you. See you soon for more collaboration!”

Facilitator 1: "Lovely to be part of this group." (Course 2: Reflective Comments).

\section{CONCLUSION}

This article explored how a diffractive reading of Slow pedagogy through an ethic of care framework illuminates the web of interrelationships that facilitate a climate conducive to the development of small group participants and a facilitator in professional academic development courses. The findings show how a collegial learning culture was fostered through the care ethics of attentiveness, responsibility, competence, responsiveness and trust, thus providing the environment within which to incubate a Slow pedagogy. Putting Slow pedagogy into conversation with an ethics of care helped to highlight what matters in professional academic development. Within the challenges of the neoliberalist context, these courses provided an environment that enabled and modelled a Slow pedagogy as they were informed by an ethic of care in their design and facilitation. The face-to-face and online community of practice enhanced opportunities for personal and collective growth and development towards improving practice and engaging in the scholarship of teaching and learning.

The role of the facilitator was key in exposing the small group participants not only to what might be possible in one's own pedagogical practice (Slow pedagogy) but the moral elements which make it possible to enact this (ethics of care) through the guidance of a knowledgeable, attentive and supportive network of facilitators. Access to a range of technologies for communication and learning ensured the small group participants were able to collectively share their teaching and learning interventions and receive timely and supportive feedback to adjust practice. It supported a greater level of responsiveness, deep learning and 
group cohesion. However, while technology enabled a level of Slow pedagogy it also increased the complexity and pace of engagement, a fast pace risked a lack of attentiveness to support needs. The design of these courses point to the importance of considerations in the pacing of activities to allow time for the building of community and depth of learning and feedback. Ensuring continuity of group cohesion and engagement across short courses further enabled deeper levels of affinity, caring, and trust to be developed over time. Going Slow deepened engagement and the building of trust and support in the group which helped to facilitate the online engagement. This is particularly important with the accelerated pace of engagement that technology provides and the depth of cognitive dissonance the new mastery of its affordances may require.

Incubating the potential of Slow pedagogy through an ethics of care perspective provides an enlarged perspective for re-imagining the design and delivery of professional academic development courses. Building in the elements of ethics of care and Slow pedagogy in the design of courses, professional academic development programmes can create contexts which help to build social cohesion and model ways of working and relating that can counteract the impact of neoliberalism on academics. This research highlights key and often invisible aspects of interpersonal and technology supported learning-in-community which can promote the development and flourishing of academics in higher education. While broad generalisable claims cannot be made from the case of a few participants on a course, this research does serve to highlight the importance of paying attention to all elements of care to enable a Slow pedagogy, and the need to research these aspects more deeply in professional academic development. Using the Slow pedagogy and ethics of care frameworks to diffractively read the experiences of a selected group of participants on two professional academic development courses has provided a relational ontology through which we could re-connect, re-energise and re-position ourselves to challenge the forces of fragmentation and individualism in the neoliberal higher education context. It incubated the development and sustainability of a professional learning community that has embraced Slow to thrive and survive.

\section{DISCLOSURE STATEMENT}

No potential conflict of interest was reported by the authors.

\section{REFERENCE LIST}

Barad, K. 2007. Meeting the universe halfway: Quantum physics and the entanglement of matter and meaning. Durham: Duke university Press.

Barad, K. 2014. Diffracting diffraction: Cutting together-apart. Parallax 20(3): 168-187. 
Berg, M. and B. Seeber. 2016. Slow professor: Challenging the culture of speed in the academy. Toronto: University of Toronto Press.

Biggs, J. 2014. Constructive alignment in university teaching. HERDSA Review of Higher Education 1(5): 5-22.

Boulous Walker, M. 2016. Slow philosophy: Reading against the institution. London: Bloomsbury.

Bozalek, V. and A. Dison. 2013. Using the human capabilities approach as a normative framework to evaluate institutional teaching and learning interventions at UWC. South African Journal of Higher Education 24(6): 1021-1035.

Bozalek, V., W. McMillan, D. Marshall, M. November, A Daniels and T Sylvester. 2014. "Analysing the Professional Development of Teaching and Learning at UWC from a Political Ethics of Care Perspective." Teaching in Higher Education 19(5): 447-458.

Bozalek, V., V. Mitchell, A. Dison and M. Alperstein. 2016. A diffractive reading of dialogical feedback through the political ethic of care. Teaching in Higher Education 21(7): 825-838.

Bozalek, V. 2017. Slow scholarship in writing retreats: A diffractive methodology for response-able pedagogies. South African Journal of Higher Education 27(3): 333-42

Boyer, E. L. 1990. Scholarship reconsidered: Priorities of the professoriate. The Carnegie Foundation. Jossey Bass.

Fisher, B. and J. C. Tronto. 1990. "Toward a feminist theory of care." In Circles of care: Work and identity in women's lives, ed. E. Abel and M. Nelson, 35-62. Albany, NY: SUNY Press.

Garey, A. and R. Hertz. 2014. Open to disruption: Time and craft in the practice of Slow sociology. Nashville, Tennessee. Vanderbilt University Press.

Hanson, J. 2009. Displaced but not replaced: The impact of e-learning on academic identities in higher education. Teaching in Higher Education 14(5): 553-564.

Haraway, D. 1992. The promises of monsters: A regenerative politics for inapproporiate/d others. In Cultural studies, ed. L. Grossberg, C. Nelson and P. A. Treichler, 295-337. New York, NY: Routledge.

Hartman, Y. and S. Darab.2012. A call for slow scholarship: A case study on the intensification of academic life and its implications for pedagogy. Review of Education, Pedagogy, and Cultural Studies 34(1-2): 49-60.

Joseph, T. 2017. Decolonising the curriculum/transforming the university: A reflective think piece. Presentation at the Work-integrated Learning Research Unit $15^{\text {th }}$ Anniversary Conference, 10 March 2017.

Kaiser, B. M. and K. Thiele. 2014. Diffraction: Onto-epistemology, quantum physics and the critical humanities. Parallax 20(3): 165-167.

Laurillard, D. 2013. Teaching as a design science: Building pedagogical patterns for learning and technology. Routledge.

Leibowitz, B. and V. Bozalek. 2016. The scholarship of teaching and learning from a social justice perspective. Teaching in Higher Education 21(2): 109-122.

MacLure, M. 2013. Researching without representation? Language and materiality in post-qualitative methodology. International Journal of Qualitative Studies in Education 26(6): 658-667.

McNiff, J. 2013. Action research: Principles and practice. London and New York: Routledge.

Martell, L. 2014. The slow university: Inequality, power and alternatives." Forum Qualitative Sozialforschung/Forum: Qualitative Social Research 15(3). http://www.qualitative-research.net/ index.php/fqs/article/view/2223/3692/ (Accessed 10 October 2017).

Meyerhoff, E., E. Johnson and B. Braun. 2011.Time and the university." ACME: An International Journal for Critical Geographies 10(3): 483-507.

Mountz, A., A. Bonds, B. Mansfield, J. Loyd, J. Hyndman, M. Walton-Roberts, R. Basu, R. Whitson, R. Hawkins, T. Hamilton and W. Curran. 2015. For Slow scholarship: A feminist politics of 
resistance through collective action in the neoliberal university. ACME: An International EJournal for Critical Geographies 14(4): 1235-1259.

Olssen, M. and M. A. Peters. 2005. Neoliberalism, higher education and the knowledge economy: From the free market to knowledge capitalism. Journal of Education Policy 20(3): 313-345.

Petrini, C. 2007. Slow food nation: Why our food should be good, clean, and fair. New York: Rizzoli Ex Libris,

Radice, H. 2013. How we got here: UK higher education under neoliberalism. ACME: An International Journal for Critical Geographies 12(2): 407-418.

Schneider, J. 2005. Donna Haraway: Live theory. New York: Bloomsbury.

Sevenhuijsen, S. 1998. Too good to be true?: Feminist considerations about trust and social cohesion. Institute for Human Studies, IWM Working Paper No. 3. Vienna.

Slaughter, S. and G. Rhoades. 2000. The neo-liberal university. In New Labor Forum, 73-79. Labor Resource Center, Queens College, City University of New York,

Shahjahan, R. A. 2014. Being "lazy" and slowing down: Toward decolonizing time, our body, and pedagogy. Educational Philosophy and Theory 47(5): 488-501.

Stengers, I. 2005. Deleuze and Guattari's last enigmatic message. Angelaki 10(2): 151-167.

Stengers, I. 2011. "Another science is possible!” A plea for Slow science. Faculté de Philosophie et Lettres, ULB, Inaugural lecture; Chair Willy Calewaert 2011-2012 (VUB).

Suspitsyna, T. 2012. Higher education for economic advancement and engaged citizenship: An analysis of the US Department of Education discourse. The Journal of Higher Education 83(1): 49-72.

Tronto, J. C. 1993. Moral boundaries: A political argument for an ethic of care. New York. Routledge.

Tronto, J. C. 2010. Creating caring institutions: Politics, plurality, and purpose. Ethics and Social Welfare 4(2): 158-171.

Tronto, J. C. 2013. Caring democracy market, equality, and justice. New York: New York University Press.

Ulmer, J. B. 2017. Writing slow ontology. Qualitative Inquiry 23(3): 201-211.

Van der Tuin, I. 2011. A different starting point, a different metaphysics: Reading Bergson and Barad diffractively. Hypatia 26(1): 22-42.

Van der Tuin, I. and R. Dolphijn. 2012. New materialism: Interviews and cartographies. Open Humanities Press.

Yin, R. K. 2009. Case study research: Design and methods. $4^{\text {th }}$ Edition. Los Angeles and London: SAGE.

Zembylas, M., V. Bozalek and T. Shefer. 2014. Tronto's notion of privileged irresponsibility and the reconceptualisation of care: Implications for critical pedagogies of emotion in higher education. Gender and Education 26(3): 200-214. 